\title{
LOS ADVERSARIA DE KASPAR VON BARTH SOBRE EL TEXTO DE PACIANO.
}

\section{La persona de Kaspar von Barth}

Las fuentes de la vida y personalidad de Kaspar von Barth son ante todo sus propios escritos, en los cuales él mismo esparce datos diversos sobre su vida, sus parientes, sus amigos y su labor científica ${ }^{(1)}$.

Kaspar von Barth fue el tercero y último hijo del matrimonio Karl von Barth, Rector Magnífico de la Universidad de Frankfurt, y la hija del capitán Werner von Hackelbusch, de la antigua nobleza julia. Nuestro erudito nació en Küstrin, pequeña ciudad de Prusia situada en la confluencia de los ríos Wartha y Oder, el 22 de junio de 1587 y murió el 22 de septiembre de 1658 a los 71 años de edad. A la muerte de su padre, acaecida en 1597, cuidó de él su tío Moritz von Barth, de quien aprendió el gusto por la poesía de Horacio y de Virgilio. Más tarde tuvo por maestro a Valentín Weinreich, poeta, gramático y lógico, de quien conservó siempre un grato recuerdo. Ya desde su tierna infancia, Kaspar von Barth dio muestras de una inteligencia privilegiada y superdotada de una forma increíble: a los tres años ya sabía leer y escribir; a los nueve se sabía ya de memoria comedias de Terencio; a los dieciséis escribió una Commendatio de lingua latina et scriptoribus latinis, publicada por Christ. Becmanni en Wittenberg el año 1608. Trata esta Commendatio sobre el mejor uso de los autores latinos y sus ediciones y supone unos grandes conocimientos filológicos. Se educó y vivió Kaspar en el espíritu de la teología luterana. Su ciencia y erudición extraordinarias despertaron la admira-

1.- La mejor investigación, aunque no exhaustiva, acerca de K. v. Barth es JohanNes Hoffmeister, Kaspar von Barths Leben, Werke und sein deutscher Phönix, Heidelberg 1931. La Herzogsbibliothek de Wolfenbüttel guarda en sus fondos manuscritos una colección de cartas de K. v. Barth de sus años jóvenes. 


\section{A. Anglada}

ción de sus profesores, quienes le llamaban Juventutis literatae vera smaragdo y Sacerdos Sophiae. Kaspar escribió sobre Claudiano, Febadio, Calpurnio, Petronio y el Pastor Hermae entre otros muchos y variados temas.

\section{La obra "Adversariorum Commentariorum libri LX"}

Una de las obras más importantes y conocidas de Kaspar von Barth son sus Casp. Barthi Adversariorum Commentariorum Libri LX. Quibus ex universa antiquitatis serie, omnis generis, ad vicies octies centum, auctorum, plus centum quinquaginta millibus, loci; tam gentilium, quam christianorum, Theologorum, Jurisconsultorum, Medicorum, Philosophorum, Philologorum, Oratorum, Rhetorum etc. obscuri, dubij, maculati, illustrantur, constituuntur, emendantur, cum rituum morum, legum, sanctionum, Sacrorum, Ceremoniarum, pacis belliq; artium, formularum locutionum denique, Observatione et elucidatione tam locuplete et varia, ut simile ab uno homine nihil unquam in litteras missum videri possit. Eduntur praeterea ex vetustatis monumentis praeclara hoc opere non pauca, nec visa hactenus, nec videri sperata. Cum undecim indicibus: VII auctorum, $I$ rerum et verborum. Francofurti, Sumptibus Johannis Persii Bibliopolae Francofurtensis Anno M.DC.XXIV ${ }^{(2)}$.

La palabra Adversaria es un término de origen comercial con el significado de notas rudas y provisionales. La Filología de los siglos XVI y XVII la empleó para designar el género de Colectáneas, Misceláneas, Ablegmina y Críticas escritas a imitación de la famosa Miscellaneorum centuria prima de Poliziano, aparecida en Florencia el año 1489. A fines del siglo XVI los Adversaria adquirieron un carácter particular por el ideal de totalidad que pretendían tener los filólogos. El modelo de los de Kaspar von Barth fueron los célebres Adversaria en 30 libros del francés Adrien de Turnèbe, editados en Basilea el año 1580 y en Estrasburgo el 1600 y que constituían una amplia enciclopedia de loca classica, enmendados no pocas veces con superficialidad. Ya como el mismo título lo indica, los Adversaria de K. von Barth se distinguen tanto por su extensión (más de tres mil columnas de doble folio en apretada impresión) como por el contenido polifacético. Están concebidos no como una obra de unidad uniforme, sino como el resultado de sus investigaciones hasta 1624. El autor demuestra gran interés por la Edad Media; sobre todo por editar textos medievales. Para él la Filología es la commentatio sacrarum litterarum $^{(3)}$. Deseaba que sus comentarios fuesen estimados como obras estilísticas y fruto de su memoria. La labor principal radica en la acumulación de lugares paralelos, de los que se sirve Barth para demostrar, aclarar y defender significados y lecturas. Semejante acopio de citas fue criticado ya por sus contemporáneos. L. von Urlichs ${ }^{(4)}$ advierte que en los Adversaria de Barth

2.- La primera edición es del año 1624, en dos volúmenes. La segunda, del año 1648, reproduce exactamente la anterior en un solo tomo.

3.- $\quad$ Adv. lib. xlviii cap. 2 col. 2240.

4.- Grundlegung und Geschichte der klassischen Altertumswissenschaft : I. Müller, Handbuch der klassischen Altertumswissenschaft. Einleitende und Hilfsdisciplinen. Nördlingen 1886 p. 67. 
se descubre de la forma más sorprendente aquel manierismo que tanto gustaba de reunir anotaciones dispersas sobre los temas más diversos. Informa de que esta obra da testimonio del mal gusto de la época, que contiene una gran ciencia, pero desordenada, falta de acierto en la crítica, llena de datos mediana o completamente falsos. "Los Adversaria", afirma, "pueden usarse únicamente con gran precaución".

\section{Comentarios sobre Paciano}

La noticia de Jerónimo.

K. von Barth cita el cap. 106 del De uiris inlustribus de Jerónimo en estos términos:

"Hieronymus Catalogo: Pacianus in Pyrenaei iugis Barcilonae Episcopus castitate et

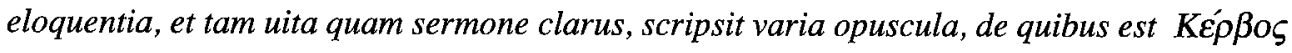
et contra Novatianos".

Esta cita reproduce el texto latino de la edición de Erasmo de 1516 con la sustitución de

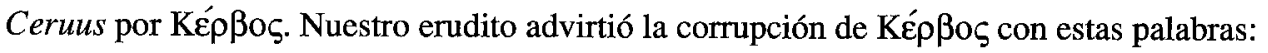

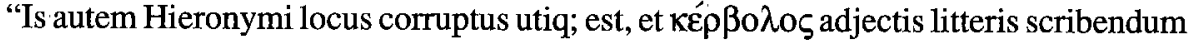
a verbo nimirum $\kappa \varepsilon \rho \beta 0 \lambda \varepsilon \tilde{\imath} v$, quod est cōviciari, et ex locis hic adscriptis ipsiusmet Paciani nostri. Videtur vero Cervolus hic idem esse cum Symphoriano illo quem et in Epistolis ut conviciatorem traducit"(5).

La Zentral- Zürich Kantons-, Stadt- und Universitätsbibliothek custodia con la signatura C 11 el ms. que contiene la traducción griega del De uiris inlustribus de Jerónimo ${ }^{(6)}$. Concurre en este manuscrito una circunstancia muy particular por cuanto Isaac Voss receló de la autenticidad del exemplar emendatum et vetustum mencionado ufanosamente por Erasmo. Fundaba sus sospechas en la deficiencia del griego de la traducción, el cual revelaba un mal conocedor de la lengua ${ }^{(7)}$. Es una pura fantasía del docto roterdamense que el traductor griego hubiera sido Sofronio, pues este nombre no aparece por ningún lado en el manuscrito, excepto en è cap. $134^{(8)}$.

Erasmo jamás llegó a conocer las obras de Paciano, por la simple razón de que la editio princeps sale a la luz en $1538^{(9)}$, dos años después de la muerte del insigne holandés (1467-

5.- $\quad$ Adv. lib. xliii cap. xv col. 1957.

6.- H. OMont, Catalogue des manuscripts grecs des bibliothèques de Suisse: Centralblatt für Bibliothekswesen 3 (1886) pp. 385 y 452.

7.- $\quad$ G. WentzeL, Die griechische Übersetzung der Viri illustres des Hieronymus: Texte und Untersuchungen zur Geschichte der Altchristlichen Literatur 13, 3 (1895) p. 9.

8.- C. Albrecht, Der Schriftstellerkatalog des Hieronymus: Theologische Literaturzeitung 18 (1895) pp. 475s. Véase un breve resumen en PH. H. Peyrot, Paciani Barcelonensis Episcopi Opuscula, Zwolle 1896, Amsterdarm 1969 (reprint.), p. III n. 7.

9.- Sobre esta edición véase Angel Anglada, La editio princeps de las Obras de Paciano de Barcelona: Miscellània Sanchis Guarner II pp. 17 - 22. Quaderns de Filologia. Universitat de València 1984. 


\section{A. Anglada}

1536). Así se comprende que por falta de información Erasmo interpretase Ké $\rho \beta o \varsigma$ como el nombre del hereje contra quien escribió Paciano. El texto en el comentario erasmiano reza:

"116 Pacianus 1 in Pyrenaei iugis, Barcilonae episcopus, castitate et eloquentia, et tā vita q sermone clarus: scripsit varia opuscula ${ }^{2}$, de quibus est Kع́ $\rho \beta o \zeta$, et cōtra Novatianos. Sub Theodosio principe iam vltima senectute mortuus est". Con la traducción falsamente atribuída

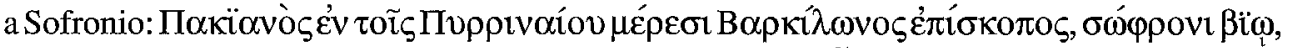

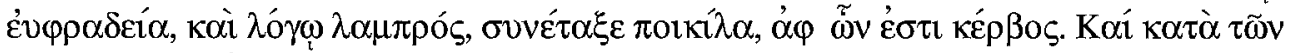

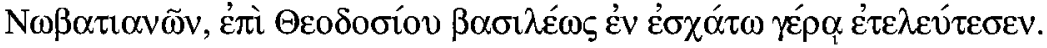

“1 Martianus ( sic). Alij Datianus, sed utrumque mendosè, cùm legendum sit Pacianus, cuius et postea meminit in Dextro filio.

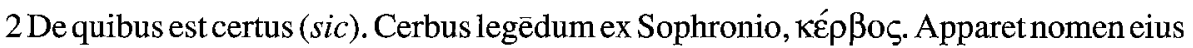
esse adversum quē scripsit.

Erasmi Roterdami in Catalogum scriptorum ecclesiasticorum Scholia. Horatius Dexter, Sophronius, Hieronymi familiaris, qui librum hunc Graece vertit, indicat hunc Dextrum fuisse praefectum praetorio ${ }^{(10)}$.

Este escolio de Erasmo dio lugar a las más inesperadas conjeturas acerca del significado y contenido de Ceruus. K. v. Barth descubrió cierta irregularidad en el texto griego y vislumbró con algún acierto la identidad del Képßoৎ del catálogo jeronimiano con el Cervulus del libro De Paenitentibus ${ }^{(11)}$ de Paciano. Llevado, no obstante, por la afirmación del erudito de Rotterdam "Apparet nomen eius esse adversum quem scripsit", entendió que en vez de кépßo

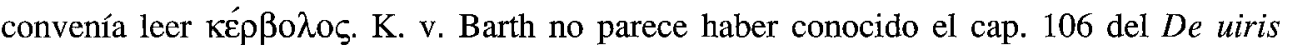
inlustribus más que a través de la edición y comentario erasmianos, pues si hubiese consultado el original latino es de suponer que más bien habría pensado en Ceruus en el sentido de Ciervo.

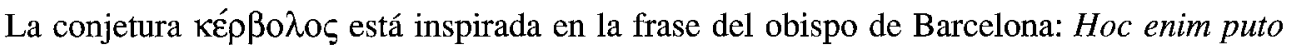
proxime Cervulus ille profecit, ut eo diligentius fieret, quo inpresius notabatur. Nuestro docto de Küstrin prosigue en su profundización, aunque no sin desviarse, interpretando el significado

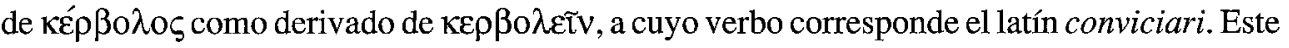
verbo le trae al pensamiento las palabras que Paciano dirigió a su corresponsal Simproniano, a quien por error llama Sinforiano: Conviciaris. Et ecce non moueor ${ }^{(12)}$ y de ellas concluye arbitrariamente que кé $\beta$ $\beta \lambda_{0 \varsigma}$ es Simproniano, confirmando así el aserto infundado de Erasmo.

10.- Sobre la identidad de Dextro, hijo de Paciano, con Nummius Aemilianus Dexter, véase H. M. JonEs - J. R. Martindale - J. Morris, Prosopography of the late roman empire. Cambridge 1971 I p. 251.

11.- Desde la editio princeps casi todas las ediciones titulan este opúsculo indebidamente Paraenesis ad Poenitentiam. Sobre el título genuino véase: Angel Anglada, Las Obras de Paciano publicadas por $V$. Noguera y Edición crítica del Liber de Paenitentibus. Universidad de Valencia 1982 pp. 19s.

12.- $\quad$ Ep II 3,1 . 
Semejante interpretación erasmio-barthiana, por así decir, pasó a las notas de no pocas ediciones del De uiris inlustribus hasta la Patrologia Latina de Migne, que reproduce todavía la nota de Vallarasio (13): "Al. Cerbus, et Képßoৎ cujus nominis variae sunt doctorum hominum interpretationes. Ea verisimilior videtur cl. Fabricii ${ }^{(14)}$, quae fert, Pacianum hunc ideo libro suo titulum fecisse, Cervum, sive Cervulum, quod perstringeret ineptum morem quorundam christianorum in Hispaniis, qui Kalend. Januarii se in cervorum, sive aliarum ferarum habitum mutabant. At nisi si Cervus de nomine ludus ille popularis tunc appellaretur, quod vetere aliquo testimonio probandum in primis fuisset cur sumerent a cervo nomen, non a leone, capra, etc., qui foras promiscue omnes induebant?". Migne llega incluso a preferir la interpretación de K. v. Barth, sin conocer su nombre, cuando añade: "Proprius mihi videtur librum inscriptum fuisse Cervulum, nomine a Graeco $\kappa \varepsilon \rho \beta o \lambda \varepsilon \tau \tau$ derivato, quod est conviciari, aut maledicere, unde

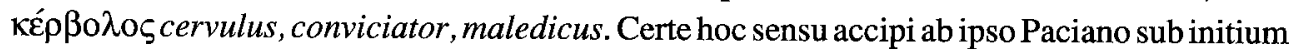
Paraenetici ${ }^{(15)}$ apparet:" Hoc enim puto proxime Cervulus ille profecit, ut eo diligentior ${ }^{(16)}$ fieret quo inpressius notabatur. Et tota illa reprehendendi ${ }^{(17)}$ dedecoris expressi ac saepe repetiti, non compresisse videatur sed erudiisse ${ }^{(18)}$ luxuriam. Me miserum. Quid ${ }^{(19)}$ ego facinoris admisi! Puto nescierat cervulum facere, nisi illis reprehendendo monstrassem".

En una nota a pie de página al Contra Rufinum de Jerónimo sospecha también Migne ${ }^{(20)}$ que en la frase ad struendam mihi calumniam cernuus quizás debería hacerse una corrección sustituyendo cernuus por cervulus, en virtud precisamente de que Paciano escribió un libro titulado Cervulus, palabra que significa Calumniator y cervulum facere, calumniari.

R. Grave ${ }^{(21)}$ en el siglo XVII había anotado respecto de "De quibus est Képßos "hoc omittit codex noster, ideo forte quod ignorarent scribae, quid sit Ké $\rho ß o \varsigma$. Docta est Colomesii observatio ex MSC codice Bibliothecae Lambethanae legendum esse: De quibus est Cervus. Képßo $\varsigma_{\text {enim }}$ ex Sophronii versione in Latinum textum irrepsisse opinatur, cum Cervus genus esset lusuum, quibus gentiles in Gallia caperentur, quemque morem Pacianus libro castigaverit, cui titulus: Cervus. Ut accedam huic sententiae, plurium codicum requiro auctoritatem".

13.- Sancti Eusebii Hieronymi Stridonensis Presbyteri Operum tomus secundus... studio et labore Domini Vallarasii Veronensis Presbyteri, Veronae $1735 \mathrm{col} 923$ n. e. f.

14.- Jo. Alberti Fabrici, Bibliotheca Latina Mediae et Infimae Aetatis, Florentiae 1858 p. 180.

15. K. von Barth es el primero y casi el único editor que da el título de Paraeneticus al De Paenitentibus.

16.- La lectura gemuina es diligentius.

17.- La lectura genuina es reprehensio.

18.- La lectura genuina es erudisse.

19.- La lectura genuina es Quod. En mi edición de 1982 escribí Quid, que ahora no me parece la lectura genuina.

20.- $P L 23$ col 429.

21.- S. Hieronymi Catalogus Scriptorum Ecclesiasticorum seu De Viris Illustribus liber. Cum notis Erasmi Roterdami, Mariani Victorii, Henrici Graevii, Auberti Miraei et Io. Alb. Fabricii, Francofurti et Lipsiae 1722 p. 292. 
El contenido tan erudito de la nota de Colomiés, confirmado por Grave, es considerado sólo como verosímil por Fabricio ${ }^{(22)}$ :

"Verisimile est Pacianum libro suo, qui hodie non exstat, titulum fecisse Cervum, sive Cervulum in quo perstrinxit ineptum morem quorundam christianorum in Hispania, qui Kalendis Januariis se in cervorum vel aliarum ferarum habitum commutabant. Hoc idem Pacianus vocat cervulum facere sub initium Paraenetici".

Fabricio aduce a continuación toda una serie de testimonios de eruditos contemporáneos suyos que tratan de esta fiesta, tales como Sirmond, Colomiés, Martino Lipenio, Du Cange, Jacobo Posino, Egidio Ménage, Juan Reiske y el concilio de Auxerre ${ }^{(23)}$. El Maestro Diago ${ }^{(24)}$ recuerda la interpretación de Erasmo, repetida por V. Noguera ${ }^{(25)}$ sin indicación alguna. Por si todo este embrollo fuera poco, vino a sumarse a la confusión una errata de imprenta que sufrió la Bibliotheca Sanctorum Patrum de Marguerin de La Bigne ${ }^{(26)}$ en la segunda edición, del año

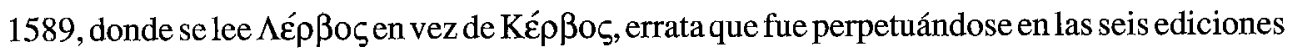
posteriores de la Bibliotheca. Así se explica que Nicolás Antonio ${ }^{(27)}$ escribiera $\lambda \varepsilon ́ \rho \beta o \zeta, ~ p e r o$

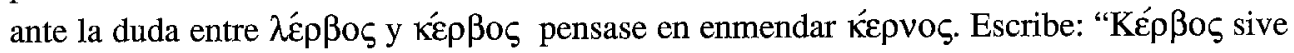
huius Graecae appellationis opusculum, quod S. Hieronymus laudat, hodie non exstat; nec item

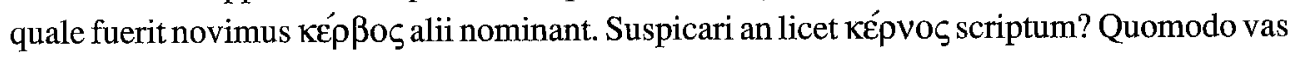
quoddam fictile audiebat in loculos distinctum, quod variis fructibus onustum sacris adhibere solebant veteres. Varium enim opus si tale fuit, non ineptè, uti \& $\pi \varepsilon ́ \pi \lambda \sigma \varsigma, \sigma \tau \rho \tilde{\omega} \mu \alpha$,

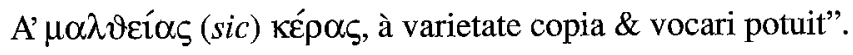

La tan poco feliz intuición de Erasmo fue evolucionando, pues, hasta ir a parar, tras dos siglos de embrollo, a una supuesta obra miscelánea de temas antiheréticos diversos.

Ph. H. Peyrot ${ }^{(28)}$ inicia el camino de retorno al buen sentido. Después de citar a Voss padre, quien había asentido a la opinión de Erasmo aceptando la traducción griega del De uiris inlustribus como de Sofronio, y a Isaac Voss hijo, quien negó la probabilidad del aserto erasmiano, se adhiere a la opinión de Colomiés e identifica con toda seguridad el Ceruus de Jerónimo con el Ceruulus de Paciano, cuyo diminutivo explica por el desprecio con que los escritores eclesiásticos tratan del juego de "hacer el ciervo': "Forma diminutiva haud scio an sit explicanda e contemptu, quo de ludo illo agunt ecclesiae scriptores".

22.- L.c.

23.- Parte de estas referencias puede hallarse en M. Mestin, La fête des Kalendes de janvier dans l' empire romain. Étude d' un rituel de Nouvel An. Collection Latomus vol. 115, Bruxelles 1970 pp. 52, 114, 117.

24.- Historia de los Victoriosísimos Antiguos Condes de Barcelona, Barcelona 1603 pp. 33va.

25.- D. Paciani episcopi Barcilonensis Opera quae extant. Discurso Preliminar p. xxxix n. 1.

26.- Sobre esta edición véase: Angel Anglada, El texto de Paciano en la 'Bibliotheca Patrum' de Marguerin de la Bigne: Homenaje a Pedro Sáinz Rodríguez, Madrid 1986 I pp. 309 - 337. En el stemma de la pág. 323 debe corregirse la línea que deriva la editio princeps de $\alpha$, pues deriva de $R$.

27.- Bibliotheca Hispana Vetus, Madrid 1788 II p. 197 cap. 7 n. 241.

28.- Paciani Barcelonensis Episcopi Opuscula, Zwollae 1896 p. III. 
L. Rubio ${ }^{(29)}$ proyecta un haz de luz meridiana y desanuda el enredo definitivamente con esta nueva precisión:

"Titubearon los humanistas, y siguen titubeando hoy los autores, sobre el título exacto que Paciano habría dado a su tratado. Según la Paraenesis, el título era Ceruulus; en la tradición manuscrita de San Jerónimo generalmente aceptada, el título es Ceruus. Parece lógico que en la duda nos inclináramos por el testimonio del propio Paciano. Pero ni siquiera cabe dudar: en los textos que tratan del mismo tema domina la forma ceruulus; ésta encaja en el lenguaje popular de la época como es bien sabido, y es natural que una fiesta eminentemente popular se designe con la correspondiente forma popular de la palabra; además Paciano, escritor cultísimo, parece ceder con gusto al empleo de estas formas primitivamente diminutivas, pero que a finales del siglo IV más que diminutivas son dominantes y, frente a las formas clásicas, pronto quedarán como las únicas en uso en las lenguas románicas".

\section{Estima de K. v. Barth por Paciano.}

Nuestro erudito siente admiración por Paciano. Le llama respetuosamente priscus et eruditus scriptor y eruditissimi auctoris ${ }^{(30)}$. Alaba su gran conocimiento de los poetas, en especial de Virgilio. Elogia el uso que sabe hacer de los proverbios y se asombra de cuán bien aprendió las enseñanzas de la escuela hasta el punto de que sus obras guardan un cierto sabor a ejercicios escolares de retórica ${ }^{(31)}$. Aprecia mucho su estilo por las abundantes citas de los poetas: "Omnino autem scholam sapit sive Rhetorica Progymnasmata tota scriptio huius doctissimi auctoris". "Multa in hoc Paciano Poetarum imitatio, multa Rhetorum... Nota loca Virgilij quae alludit. Sed et priora verba nullo negotio in Hexametros redigas; quod genus scribendi tum singulare habebatur; et objicitur Paciano ab adversariis"(32).

Con estas observaciones K. v. Barth se adelantó en aspectos muy importantes que merecen hoy alguna mayor precisión. Si el texto de Paciano parece fácil de poner en verso hexámetro, ello refleja la práctica escolar de pasar el ritmo de poesía a ritmo de prosa y viceversa $^{(33)}$, aunque no faltan miembros que llegan a constituir un hexámetro más o menos

29.- San Paciano. Obras. Universidad de Barcelona 1958 p. 10.

30-. Adv. lib. xlii cap. xxvii col. 1920; lib. xliv cap. xxx col. 2051.

31.- Esta reminiscencia escolar se siente en toda la obra de Paciano. No menos en el ritmo de su prosa.

32.- El plural adversariis es una inexactitud de Barth, pues el único adversario conocido del Obispo de Barcelona es Simproniano.

33.- Véase L. Rubio, Op. c. pp. 25 s. 


\section{A. Anglada}

completo $^{(34)}$. No es cierto, en cambio que tal forma de escribir fuese singular en los tiempos del obispo de Barcelona. Basta con dar una mirada a la bibliografía de los estudios sobre el ritmo de la prosa latina de diversos autores del siglo IV. El reproche irónico de cuán bello era el estilo de Paciano se debe a su único adversario, Simproniano ${ }^{(35)}$.

\section{Título del 'Liber De Paenitentibus' de Paciano.}

Corresponde a $\mathrm{K}$. von Barth el mérito de haber sido el primero en advertir que el epígrafe Paraenesis ad Poenitantiam no convenía al contenido, aunque en su edición de este opúsculo escribe Paraeneticus ad Poenitentiam ${ }^{(36)}$. En los Adversaria ${ }^{(37)}$ indica que el título debería ser De Poenitentium curatione a tenor del comienzo: "Etsi aliquotiens, tumultuose licet, de paenitentium curatione non tacui"(38). La expresión de paenitentium curatione se halla también en el Tratado ${ }^{(39)}$ antinovacionista, cuando Paciano recomienda a su corresponsal que se lea bien el De Lapsis de Cipriano si quiere conocer la doctrina del santo obispo de Cartago acerca del tratamiento que debe aplicarse a los penitentes: "Lege igitur diligentius Cyprianum meum, lege totam de lapsis epistolam, lege aliam quam ad Antonianum dedit, ubi exemplis omnibus Nouatianus urguetur: iam scies quid de paenitentium curatione pronuntiet"(40).

Una cierta dificultad ofrece el pasaje: "Iam recte a me positum vides, cum de paenitentium curatione tractarem dixisse dominum: 'Non est opus sanis medicus, sed male habentibus"(41), pues esta cita bíblica no aparece en ningún otro lugar de la obra de Paciano. Un tenue haz de luz proyecta la segunda persona del singular vides, por cuanto parece dar a entender que fue en la carta primera dirigida a Simproniano. En ella, al comienzo de la segunda parte,

34. Por ejemplo, Quid enim ego dixeram, aut quos Vergilii uersus enarraram (Ep II, $I V I)$ el miembro aut... enarraram constituye casi un hexámetro entero. Attendite si non creditis (Paen XI 5, 315) es más de medio hexámetro. Quizás influyó también en este juicio de Barth el ritmo de la prosa de Paciano. Cf. ANGEL ANGLADA, Consideraciones sobre el ritmo de la prosa de Paciano en Actas del I Simposio de Latín Cristiano. Salamanca 1990 pp. $21-43$.

35. Ep II 4, 5 .

36. Zwickau 1655, junto con el Pastor Hermae y otros escritores: Claudiani Eccdicii Mamerti 'De Statu animae libri III'; Gregorii Thaumaturgi libellus de anima; Hermae, vetustissimi Theologi, Pastor et Paciani, Episcopi Barcinonensis, 'Paraeneticus ad Poenitentiam'. Cygneae 1655. El llamado Paraeneticus se halla en las págs. 934- 952.

37. Lib xliii cap. xv col. 1956.

38. Paen I 1,3 .

39. Tract (= Ep III) xiv 4. Sobre el título Tractatus en vez de Epistula III véase mi comunicación en el VII Congreso Español de Estudios Clásicos titulada El género literario de la Carta Segunda de Paciano. II, pp. 457-467, Madrid 1989.

40. Tract. XXIV 2.

41. $I b$. xiv 4 . 
donde se empieza a tratar el tema de la penitencia, leemos esta frase similar a la de la cita bíblica: "Nec sanis medicinam, sed male habentibus nuntiamus".(42)

Si el erudito de Küstrin advirtió con acierto que el contenido del opúsculo no era precisamente una exhortación, sino el tratamiento que debían seguir los penitentes para curarse de la herida del pecado, el no haber podido conocer los manuscritos le impidió llegar a determinar el verdadero título, que reza De Paenitentibus. De hecho, las propias palabras de Paciano jamás dan motivo para pensar que se trate de una exhortación. En este título De Paenitentibus influyeron las dos fuentes principales que siguió Paciano en su opúsculo como son De Paenitentia de Tertuliano, que transcribe a veces incluso literalmente, y De Lapsis de Cipriano, reproducido en algunos casos también al pie de la letra. El significado sinónimo de lapsus y paenitens ${ }^{(43)}$ aparece claramente en estos textos de la correspondencia de Cipriano:

"Ut ad fouenda et sananda lapsorum uulnera consilium salubre teneamus"(44), y del anónimo Ad Novatianum:

"Istis igitur tot et tantis malignis spiritibus infestantibus et in lapsorum necem insurgentibus prouisa est uulneratis salutis uia, ut quibuscumque uiribus possent toto se corpore protrahere, castris suis recipere, quibus recepti possent medellis spiritualibus uulnera sua curare"(45).

Era lapsi un término militar predicado de aquellos soldados heridos que eran llevados al campamento para recibir el tratamiento adecuado. Este carácter sinónimo de lapsi y paenitentes explica sin dificultad la combinación de los títulos de las dos fuentes dando como resultado De Paenitentibus, que conserva el Reginensis Lat. 331 y en general los otros cuatro manuscritos, derivados de éste.

Paen VIII 1, 192s (Adv. lib. xiv cap. viii cols. 2070s)

"Viues tot animarum reus? Excusaberis cum tibi communionem suam inputauerint innocentes, cum te Ecclesia dixerit suae cladis auctorem?".

En relación con communionem Barth exclama sorprendido que no debe decirse communionem, sino todo lo contrario, nada menos que discommunionem, lo que procura demostrar con ejemplos de compuestos de dis-. La supuesta analogía no llega a tener fuerza probativa por la sencilla razón de que discommunio no sólo no está atestiguada en la literatura latina, cristiana o pagana, ni en las lenguas románicas, sino que, además, contraviene al sentido, pues ¿cómo se podría imputar al pecador la discommunio si ésta implica ausencia de relación con los inocentes?

\footnotetext{
42.- $E p \mathrm{IV} 1$.

43.- H. Косн, Cyprianische Untersuchungen, Bonn 1926, pp. 380s.

44.- Ep. xxxiv. iii 1.

45.- Ad Nouatianum iv (CCh SL IV p. 142, 9 -13).
} 


\section{A. ANGlada}

A. Gruber ${ }^{(46)}$ en el apartado Wörter, die sich bei Pacian in einer neuen Bedeutung vorfinden interpreta communio en el sentido de contagio. Semejante equivalencia no tiene visos de probabilidad si recordamos que la medicina antigua no conocía el concepto de contagio o transmisión de la enfermedad por el contacto con el enfermo, porque en la antigüedad los médicos no solían pensar que un germen patógeno se propagase de un individuo a otro. La causa de las enfermedades de peste radicaba necesariamente en un factor común a todas las personas afectadas, y este factor no era otro que el aire respirado ${ }^{(47)}$. Debe desecharse, pues, esta interpretación de contagio, porque entraña un concepto ajeno a la cultura de la época de Paciano. Entendió V. Noguera que communionem significa aquí la comunión eucarística y traduce: "¿Qué excusa alegarás cuando tantos inocentes te echen la culpa de sus comuniones mal hechas?"(48). Es incomprensible cómo A. Blaise ${ }^{(49)}$ haya podido apartarse del concepto de communio hasta traducir souillure: lorsque les innocents t' imputeront la souillure contractée à ton contact. En el latín de los cristianos primitivos communio corresponde al término griego no menos cristiano Kolvwví $\alpha$, que entraña la idea de participación a la manera como media algo común entre quien toma y da parte de lo mismo. Nuestro pasaje repite el contenido del precepto de San Juan ${ }^{(50)}$ a Electa de negar el saludo al hereje, porque quien saluda al malo comunica en sus malas obras:

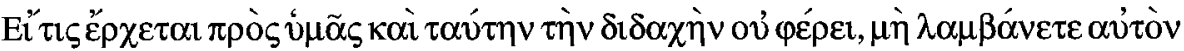

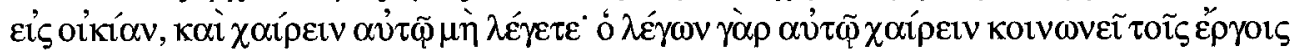

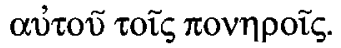

Si quis uenit ad uos et hanc doctrinam non affert, nolite recipere eum in domum, nec Aue ei dixeritis; qui enim dicit illi Aue, communicat operibus eius malignis.

Así pues, el cristiano que participara de Cristo en la comunidad cristiana en la que existiera un pecador, tendría, según el texto de Paciano, también una participación en las malas obras del pecador y quedaría afectado de sus pecados por el hecho de mantenerle en su comunidad, de darle el saludo, el Salom, la pacem.

El texto de Paciano debe entenderse, pues, en el sentido de que el pecador hipócrita que no hace penitencia de sus pecados es responsable de la complicidad de los cristianos inocentes que participan de su culpa por haberle admitido en su comunión, en su comunidad. La traducción es, por tanto:

46.- Studien zu Pacianus von Barcelona, München 1901, p. 46.

47.- D. Gourevitch, Peut-on employer le mot d' infection dans les traductions françaises de textes latins?; MrR Kо D. Grmek, Les vicissitudes des notions d'infection, de contagion et de germe dans la médicine antique en Centre Jean Palerme, Textes Médicaux Latins Antiques. Mémoire V, Saint-Étienne Université 1984 pp. 49- 52; 53- 70.

48.- Op.c.p. 36 .

49.- Dictionnaire Latin-Français des Auteurs Chrétiens. Turnhout 1954 p. 178 communio 7.

50.- 2 Ioh 11. Fr. Yves M.-J. Congar, Note sur les mots "Confession", "Église" et "Communion" en Irénikon 23 (1950) pp. 3 - 36 no guarda relación con el tema que tratamos. 
"¿Tendrás excusa cuando los inocentes te imputen su complicidad en tus pecados por haberte dado parte en su iglesia?".

Paen VIII 3, 199 - 204 (Adv. ilb. xlv cap. viii col. 2071)

Meminimus quosdam remota etiam et verecunda membrorum non erubescentes in ferro et cauterio et gravissima illa pulveris mordacitate durasse.

Comenta K. v. Barth:

"Pulveris quidem communis vis siccatoria, (sic) ut scribit Plinius libro xv cap. xix. Sed hic de medicato aliquo, tum vulgo noto, sermo est. Suspicor autem eum innui qui per excellentiam ISotheos ( $\mathrm{sic}$ ) appellatur et multis omnino malis utilissimus, ijs sanè speciebus constat quae mordacissimae habentur, ut Nitro, Salibus multis, sulphure, pipere, alumine, et talibus ejus descriptionem habes apud Alexandrum Trallianum libro xi".

En el pasaje aludido Plinio habla del poder de secar que tiene el polvo, pero en sentido distinto. El célebre médico de Lidia del siglo VI d. J. C. describe en el lugar de referencia una sustancia en los términos de nuestro docto germano. El nombre Isotheos obedece, según $\mathrm{H}$.

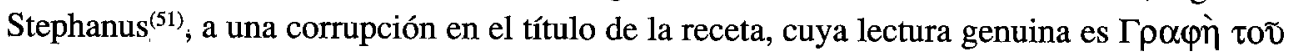
'Ivסov.

En la literatura clásica la primera vez que se habla de un medicamento consistente en unos polvos cáusticos es en la Ilíada ${ }^{(52)}$, donde se narra cómo Eurípilo cura a Patroclo la herida lavándosela primero y aplicándole después unos polvos obtenidos frotando unas raíces con las manos. Estos polvos ${ }^{(53)}$ calmaban el dolor, secaban la herida y evitaban la putrefacción y la hemorragia. La costra que así se formaba constituía una capa de protección contra las influencias exteriores dañinas. El escoliasta Eustacio $^{(54)}$ y con él otros comentaristas identifican la planta medicinal de la Iliada con la aristoloquia.

Estos polvos se obtuvieron posteriormente de plantas que sería difícil precisar y muy probablemente coincidirían con algunos de los más de cincuenta productos vegetales de la medicina hipocrática ${ }^{(55)}$.

En la literatura latina cristiana es frecuente la alusión a un polvo cáustico. Rufino: necessariam habemus interdum austerioris ac mordacioris medicamenti curam ${ }^{(56)}$. Prudencio: quam sit rationis egenis mordax et amara medella ${ }^{(57)}$. Agustín: uidete quam blandi sunt medici

51.- ThLG V p. 670 B, Graz 1954 (reprint).

52.- $\Lambda 846 \mathrm{~s}$.

53.- F. SChmiedeberg, Über die Pharmaka in der llias und Odysee. Strassburg 1918, 20 págs.

54.- H. ERBSE, Scholia Graeca in Homeri Iliadem, Berolini 1969, III pp. $291 \mathrm{s.}$

55.- HLPOCR., Пері '

56.- Apol. Orig. 8.

57.- Cath. 10, 83 (CCh SL CXXVI p. 56). 
eis quos etiam mordaciter curant ${ }^{(58)}$. Jerónimo: quod per mollitiem alicuius emplasti nequaquam sanari ualuit, mordaciori puluere et austeriori curatione sanetur ${ }^{(59)}$. También en una carta él mismo escribe: peccata tua quae sanari non poterant nisi mordacissimo puluere et ardente cauterio et ferro acutissimo, quo putridas carnes et insanabiles amputarem ${ }^{(60)}$. Paciano imita el texto de su fuente, el De Paenitentia de Tertuliano donde se lee: Miserum est sectari et cauterio exuri et pulueris alicuius mordacitate cruciari $^{(61)}$. Tertuliano hace una comparación con el dolor más terrible que se puede sufrir en un tratamiento médico, para exhortar a los pecadores a la penitencia. El pulueris mordacitate de Paciano tiene la misma finalidad. Debe entenderse durasse de la costra formada por los polvos cáusticos aplicados a las heridas, sin necesidad de atribuir al obispo de Barcelona un conocimiento especial de la medicina. Repitió con el mismo fin que su fuente una expresión casi tópica en la literatura penitencial. No es, pues, apropiada la observación de Barth de que se trate de un medicamento muy concreto, sino de los tratamientos más temibles practicados por los médicos, sin mayor precisión y repitiendo un tópico de la literatura latina cristiana.

\section{Paen X 3, $259-261$ (Adv. lib.xiv col 2073)}

Caeterum valet alioquin in his: Benè quod mediocres sumus, caeterum et illa faceremus quae quosdam et quasdam non pudet lautiores, marmoribus tegi, auro opprimi, serico fluere, cocco rubescere.

El relativo quae con que Barth cita el pasaje pretende concertar el quod de la tradición manuscrita con illa, lo que implica la discordancia con pudet, con el que quae no puede concordar por su carácter de verbo unipersonal. A la luz de la puntuación del Reginensis 331, antes y después, quod quosdam et quasdam non pudet lautiores constituye un miembro, lo que permite referir su contenido al conjunto de los infinitivos siguientes y considerar éstos como aposición de illa. De no admitir esta construcción cabe pensar en un vulgarismo. O si se quiere, admitir ambas interpretaciones. De hecho, el relativo cuius concierta con su correlativo plural praesentibus en "Vim eius, et de praesentibus aestimate. Cuius fumariola quaedam maximos montes subterraneis ignibus decoquunt"(Ib.XI,6,319).

Propone Barth la sustitución de marmoribus por margaritis arguyendo con el testimonio de Plinio: "Uniones enim contexebant ueteres in monilia integra, intersertis alijs pretiosis lapidibus, ut membra integra eis uelut tegerentur", y también: “Quin Musaeum seu conclave integrum ex margaritis constructum in spolijs Regis Asiatici cujusdam memorat Plinius" ${ }^{\text {"(62). }}$. De donde concluye: "Vides quomodo tegi margaritis dixerit Pacianus".

\footnotetext{
58.- Serm. 357, 4

59.- In Gal. 4, 20

60.- 6,77 .

61.- Paen XI 3 (CCh SL I p. 338, 9 -12)

62.- Nat. Hist. IX 112; XXXVII 14.
} 
Ph. H. Peyrot adoptó la conjetura de Barth, pero no se advierte razón alguna para que en un contexto referente al fausto no pueda tener cabida el lujo suntuoso de las casas. Tiene pleno sentido marmoribus tegi dicho de los revestimientos de mármol que decoraban los fastuosos palacios de los romanos pudientes.

Ep II,IV 3 (Adv. lib. xliii cap. xxiix col. 1983)

Confusionem ad Babyloniam linguarum quam Sacrae Salutis litterae tradunt, in distinctas centum et viginti exijsse auctores sunt scriptores Antiquitatis Christianae. Pacianus Barcellonae Episcopus Epistolâ II Latinis institutum Latinè loquentem tam accusare debebis, quam Graecè Graecum, quam Parthicè Parthum, quam Punicè Poenum. Medis, Aegyptijs, Hebraeis sua lingua est, secundum copiam domini, qui eam in centum viginti ora modulatus est. Et infra ${ }^{(63)}$. Praeter has $C$. \& XX linguas fuit adhuc alia Musarum? Aliter tamen alij nunc Arnobius Rhetor Commentario in Psalmo CIV. Septuaginta duas linguas per sucessiones filiorum Noe collegit".

En el pasaje de Paciano vio K. v. Barth una alusión a la confusión de lenguas de la Torre de Babel. La aserción de que los escritores cristianos antiguos contaron ciento veinte lenguas distintas se apoya en el único testimonio de Paciano, frente al cual cita otros que calculan setenta y dos, entre ellos Arnobio en un comentario, que por cierto no escribió.Este error debe atribuirse a un lapso de memoria en nuestro erudito.

J. B. Cotelier ${ }^{(64)}$ sospechó que debía corregrise CXX en LXX, conjetura que Noguera hubiese querido introducir en el texto, pero lo estimó demasiado atrevimiento ${ }^{(65)}$. Escribe Cotelier: "Pacianum tamen epistolâ 2. adversus Novatianos, ponere linguas CXX. Nisi si rescribendum parvâ mutatione, LXX".

En la literatura clásica una hipérbole pasó a la poesía latina como tópico para el enaltecimiento del tema que el poeta se propone cantar. El primero en acudir a esta figura es

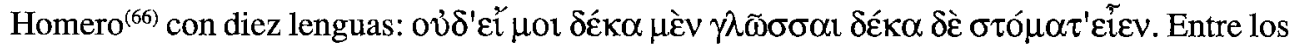
latinos imitó el primero a Homero Ennio ${ }^{(67)}$ : Non si, lingua loqui saperet quibus, ora decem sint. En un verso conservado sólo por Servio ${ }^{(68)}$, Lucrecio continúa en el mismo plagio: non mihi si linguae centum sint oraque centum, aerea vox. Con la sustitución de aerea por ferrea lo repitió

63.- IV 3 y 6.

64.- SS. Patrum qui temporibus apostolicis floruerunt Barnabae, Clementis, Hermae, Ignatii, Polycarpi Opera edita... J. B. Cotelerius.... vol. I Antverpiae 1698 p. 487 a.

65.- D. Paciani Episcopi Barcilonensis Opera quae extant, Valencia 1780 p. 118 (V).

66.- Iliada B 489s.

67.- Ann. lvxxxvii 561s. Cf. I. Vahlen, Ennianae Poesis Reliquiae, Leipzig 1928 /Amsterdam 1967, p. 103.

68.- "Non si linguae centum sint" Lucretii uersus sublatus de Homero, sed aerea uox dixit. G. THILO- H. HAGEN, Servii Grammatici qui feruntur in Vergilii carmina commentarii, Leipzig 1884/Hildesheim 1961 II p. 88, 625. 


\section{A. Anglada}

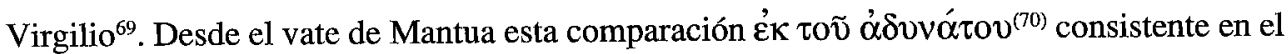
deseo de tener cien voces, bocas y lenguas se generaliza hasta el punto de que Persio ${ }^{(71)}$ escribe: uatibus mos est centum sibi poscere uoces / centum ora et linguas optare in carmina centum. En los poetas tardíos se lee aún con mayor frecuencia: in tua centenas praeconia uoces escribe Claudiano ${ }^{(72)}$, mientras Sedulio habla de cien sonidos: centenosque sonos humanum pectus anhele $t^{(73)}$. Arator ${ }^{(74)}$ : o mihi si cursus facundior ora moueret, / centenosque daret uox ferrea, lingua disserta / hac in laude sonos. Teodulfo aumenta a mil el número que los latinos habían pasado a cien: si mihi mille forent centeno in gutture linguae ${ }^{(75)}$.

Sería interminable el elenco de las distintas variedades que llegó a alcanzar esta exageración retórica pasando del número cien al mil, y más. Un extremo se aprecia en estos versos del tipo quot - tot del himno a Santa Hedwig: Quot stellae, tot encomia Hedwigis sibi vendicat / tot linguis, quot sunt folia, mens nostra hanc praedicat. ${ }^{(76)}$

La frecuencia con que aparece la expresión sobre todo en los escritores tardíos y la persistencia de las palabras linguae, ora, uoces hace pensar en un transfondo común, el cual no puede ser otro sino la escuela, en cuyos ejercicios escolares sobre el género del encomio Paciano habría practicado esta comparación.

Con esta tradición escolar se armonizaría mal la conjetura del número LXX propuesta por Cotelier. Con el carácter de castigo de la confusión de lenguas en la construcción de la Torre de Babel tampoco estarían acordes los términos: secundum copiam domini ${ }^{(77)}$ y omnium uocum modos, omnium genera linguarum a Deo inspirata retinemus, como tampoco el tecnicismo retórico modulatus est ${ }^{(78)}$.

Todo el contexto presenta un vocabulario extraño al relato bíblico, que reza en la Vulgata:

Descendit autem Dominus, ut uideret ciuitatem et turrim quam aedificabant filii Adam, et dixit: "Ecce unus est populus et unum labium omnibus: coeperuntque hoc facere nec desistent a cogitationibus suis donec eas opere compleant. Venite igitur, descendamus et con-

69. Georg II 44; Aen. VI 625s.

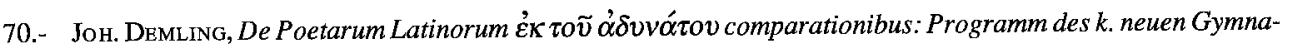
siums zu Würzburg f. d. Studienjahr 1897/8, Würzburg 1898 p. 42.

71.- Sat. V 1s.

72.- Consul. Stilichonis II 185: MGH Auct. Antiquiss. X p. 209, 22.

73.- Pasch. carm. I, 99s CSEL X.

74.- Act. Apost. I 459s PL $68 \mathrm{col} 135$

75.- Carm. 28, 9 MGH Poet. Aevi Carol. I p. 494, 7 PL 39 col. 1977.

76.- H. WALTER, Quot-tot mittelalterliche Liebesgrüsse und verwandtes en Zeitschrift für Deutsches Altertum und Deutsche Literatur 65 (1928) p. 276.

77.- PAC. Ep II IV 3.

78.- $\quad$ Ib. 6. 
fundamus ibi linguam eorum, ut non audiat unusquisque uocem proximi sui. Atque ita diuisit eos Dominus ex illo loco in uniuersas terras, et cessauerunt aedificare ciuitatem. Et idcirco uocatum est nomen eius Babel, quia ibi confusum est labium uniuersae terrae; et inde dispersit eos Dominus super faciem cunctarum regionum ${ }^{(79)}$.

En cambio, el único testimonio bíblico al cual se hace referencia es la Carta primera a los fieles de Corinto, teste apostolo, donde San Pablo escribe: Tam multa, ut puta, genera linguarum sunt in hoc mundo, et nihil sine uoce est ${ }^{(80)}$.

Si la forma sitúa este pasaje en la tradición escolar pagana, el contenido y, en parte, el léxico no son extraños a la tradición cristiana sobre la diversidad de los pueblos y lenguas que rezan y alaban a Dios. Reprochaba Celso a los cristianos que en sus oraciones se dirigían a Dios con nombres extranjeros tomados en un sentido impropio. Orígenes ${ }^{(81)}$ le replicó que los fieles de Cristo invocaban a Dios con nombres propios que se encuentran en las Escrituras Divinas y cada uno oraba y glorificaba a Dios en su lengua, pues el Señor de todas las lenguas escucha a quien le reza sea en la lengua que sea, oyendo, por así decir, una misma voz en distintos idiomas, porque Dios no es como quienes hablan la lengua que la suerte les ha deparado, extranjera o griego, y se desentienden de quienes hablan otros idiomas. Dice Orígenes:

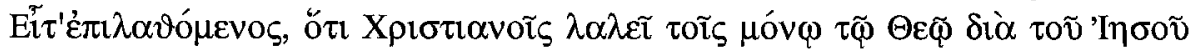

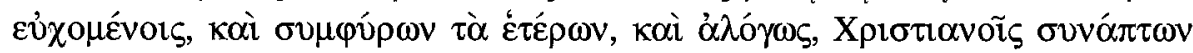

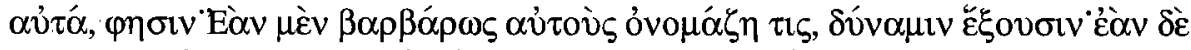

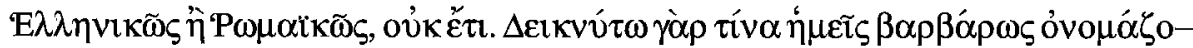

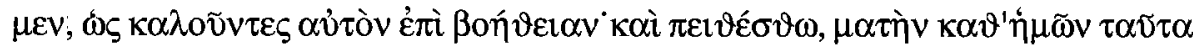

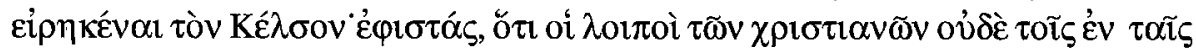

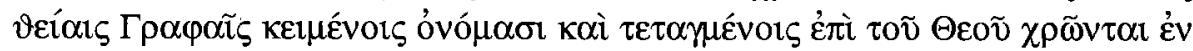

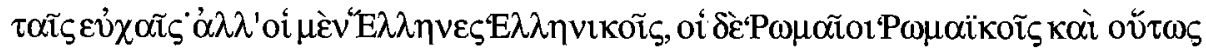

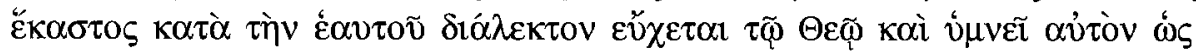

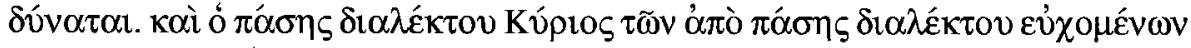

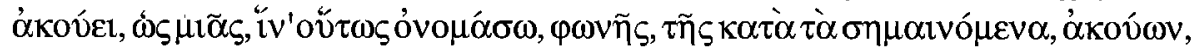

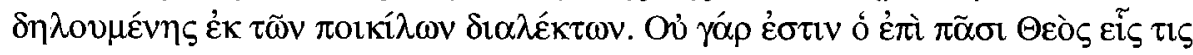

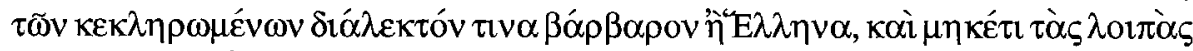

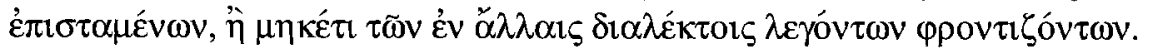

El pasaje ofrece estas correspondencias de léxico y de contenido:

\section{Orígenes}

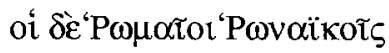

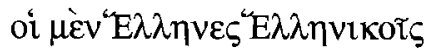

79.- Gen 11, 5 - 9.

80.- I Cor 14,$10 ; 12,10$ у 28.

81.- c. Cels. 8, $27-31$.
Paciano

Latinis institutum Latine loquentem

Graece Graecum, Parthice Partum, Punice Poenum 


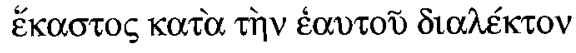

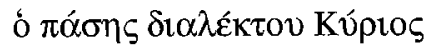

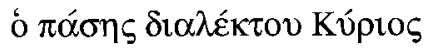

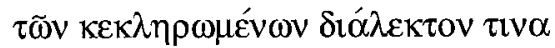

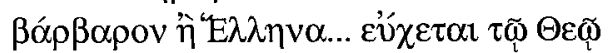

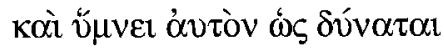

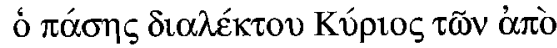

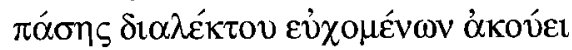

Medis, Aegyptiis, Hebraeis sua lingua est

omnium uocum modos, omnium genera linguarum a Deo inspirata retinemus

quamcumque uocem copiam Dei credimus

Latium, Aegyptus, Athenae, Thraces, Arabes, Hispani Deum confitentur

omnes linguas Spiritus Sanctus intellegit

Si Orígenes refutaba a Celso por cuanto los cristianos alaban y rezan a Dios llamándole por sus nombres, pues están en las Escrituras Divinas y Dios, Señor de todas las lenguas, escucha a cada uno en su lengua sea la que sea, Paciano arguye por la misma razón que está en su derecho de aducir un verso pagano, por cuanto Dios inspiró y modelò todas las lenguas y como Señor que es de las mismas las entiende todas. Esta mentalidad más abierta es también más reciente y empieza con Cipriano, oponiéndose a la tendencia rigorista representada por Simproniano, más antigua, que negaba a los cristianos la lectura de los poetas y escritores paganos $^{(82)}$.

Mayor dificultad ofrece la interpretación del número CXX, si realmente se quiere entender con precisión estricta. Enmarcado dentro de la tradición literaria latina pagana el número 120 no es ajeno a Hesíodo, mencionado en el texto: Praeter illas centum et uiginti linguas fuit adhuc alia musarum? Hesiodus istud in Helicone mentitus est. Los antiguos discutieron mucho sobre la época en que vivió el poeta de Ascra. Sentían una gran curiosidad por saber qué tiempo mediaba entre Homero y Hesíodo ${ }^{(83)}$. Una tradición bastante extendida contaba 120 años, cifra que por ser más común pudo haber sido también la más escolar, y como tal haberla aprendido Paciano. Tampoco resulta extraña al número de lenguas, pues, según el testimonio de Livio ${ }^{(84)}$, Publio y Gneo Escipión sometieron y unieron con lazos de amistad con

82.- H. Hagendahl, Von Tertullian zu Cassiodor. Die profane literarische Tradition in dem lateinischen christlichen Schriftum. (Studia Graeca et Latina Gothoburgensia XLIV), Göteborg 1983, especialmente pp. 74 $-93$.

83.- JАСОВ Y, Apolodors Chronik. Philologische Untersuchungen XVI. Berlin 1902, pp. 118s; del mismo, Marmor Parium. Berlin 1904 pp. 152s; RонDE, Kleine Schriften 1, pp. 39s, 71s.

84.- XXII 20, 10. 
Roma a más de ciento veinte pueblos de España:

Ex Baliaribus insulis legati pacem petentes ad Scipionem uenerunt. Inde flexa retro classis reditumque in citeriora prouinciae, quo omnium populorum, qui <cis> Hiberum incolunt, multorum et ultimae Hispaniae legati concurrerunt, sed qui uere dicionis inperiique Romani facti sunt obsidibus datis, populi amplius fuere centum et uiginti.

Ante estas consideraciones resulta evidente:

1. Que Paciano no hace la más mínima alusión al relato bíblico de la confusión de las cien lenguas en la Torre de Babel.

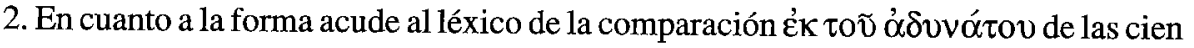
lenguas de la tradición poética latina.

3. El contenido responde a la tendencia abierta a la lectura de los escritores paganos reproduciendo una argumentación que guarda cierta afinidad con Orígenes.

4. Es más prudente, en consecuencia, no anular el problema, si realmente existe, corrigiendo con Cotelier CXX en LXX.

Ep II 5,5 (Adv. lib. xliii cap. xxix cols. 1984s)

Indentari est additis dentibus armari. Pacianus: Verum recole utrimque jam litteras, jam videbis spiculisne an floribus paginam conseramus. De similibus quidem Apostolus quos oportet indentari.

En jam litteras debe ser jam una errata de imprenta motivada por el jam inmediato siguiente o es fruto de la arbitrariedad o un lapso de memoria de Barth. De hecho, no se halla en los manuscritos ni en ninguna edición.

La cita del Apóstol pertenece a la Carta de San Pablo a Tito ${ }^{(85)}$ concerniente a la misión episcopal y más concretamente al deber de hacer callar a los charlatanes y seductores. El texto

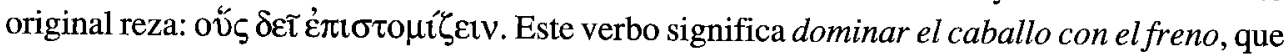
en sentido traslaticio, ya desde la antigüedad clásica es refutar o reducir al silencio. La Vulgata suaviza el significado por medio de la acepción metafórica quos oportet redargui. La versión de Paciano conserva la dureza en quos oportet indentari, en castellano "a quienes es preciso frenar con el bocado", mientras que según la Vulgata diríamos: "a quienes es preciso refutar". Lucifer de Cagliari ${ }^{(86)}$ usa redargui en la cita del pasaje paulino: quos oportet redargui; en cambio, en la exégesis escribe indentemini: Conspicis interea mandasse apostolum, ut uos ueritati resistentes indentemini episcopi interuentu. Lucifer de Cagliari confirma, pues, el significado de indentari no como "armar con dientes", sino de "reducir al silencio". Tampoco entendió el sentido V. Noguera al traducir: "devemos hincar los dientes" y cuando comenta: INDENTARI. Vox est labentis Latinitatis, quam alibi frustra quaeras. Significat dente infringe$r e^{(87)}$.

85.- 1, 11. Para el significado, véase Fr. ZoReLL, Lexikon Graecum Noui Testamenti. Parisiis 1904/ 1961 col. 496.

86.- Athan. lib. II, xxvii (CCh SL VIII p. 122, 21)

87.- Op. c. pp. 110 y $229(\mathrm{~N})$. 


\section{A. Anglada}

Seguidamente Paciano aludiendo a un refrán ${ }^{(88)}$ añade que no pelea como las fieras salvajes, sino como las palomas que besan y no muerden: Sed attende. Nos tecum quasi columbae, ore potius, quam dente confligimus. Con el tono de amistad y afecto con que discute el obispo no se avendría un verbo como "armar con dientes" al adversario para que luche como un lobo contra una paloma y la mate, ni tampoco un significado como "hincar los dientes en el adversario".

Conclusión: La interpretación de Barth es opuesta al sentido del verbo griego

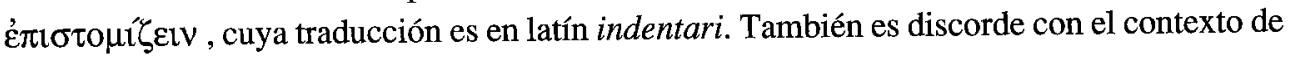
Paciano.

Paen II 2, 32-37 (Adv. lib.xliii cap. xv 1957s)

Fibula pro Enchiridio aliquo aut tabellâ memoriali sive Breviculo, ut vocant, aut laterculo, in quo aliquid memoriae gratiâ notatur, posita est his verbis. Praeterea nullus existimet hunc ipsum de poenitentiae institutione sermonem, solis tantummodo poenitentibus ordinatum; cum in hanc quasi fibulam, totius Ecclesiae disciplina notetur. Servat Germanismus hanc vocem. Fibulam enim dicimus ex qua pueri primum elementa litterarum agnoscere et pronunciare discunt. Sic Tertullianus fibulam vocat scultellum sive ratinale illud quod portabat Aaron lib. de Idololatria cap. xix ${ }^{(89)}$ Virgam portavit Moyses, fibulam et Aaron, cingitur loro et Iohannes, agmen agit et Iesus Nave.

Es éste el mejor comentario de K. v. Barth a Paciano y su desconocimiento u olvido ha sido en perjuicio no sólo de la interpretación del pasaje sino también de la constitución del texto.

Fue K. v. Barth el único en entender estas líneas. Jean du Tillet, ignorando qué relación podría guardar "anotar" con "hebilla", indicó en el margen alias coarctetur respecto de notetur, nota que Galesinio estimó en tanto que editó nodetur en vez de notetur como verbo naturalmente más acorde con el concepto de hebilla. Afortunadamente M. de la Bigne no conoció la edición de 1564 y copió en el margen la nota de la editio princeps, circunstancia que permitió a K. v. Barth leer el texto genuino. En confirmación de su acierto aduce un paralelismo de Tertuliano.

No tuvo mucha dificultad J. F. Gronov para encontrar un motivo de censura. Alegó simplemente la etimología del alemán Fibel, todavía hoy generalizada, de que es corrupción infantil por Bibel. Escribe así el erudito holandés ${ }^{(90)}$ :

Pro notetur, alii legunt coarctetur. Alii observant Germanismum vocem fibulae servare pro libello seu tabellis, in quibus quid notetur vel scribatur: ita enim dici ex qua pueri elementa

88.- А. Отто, Die Sprichwörter und sprichwörtlichen Redensarten der Römer, Leipzig 1890/ Hildesheim 1962 p. 88 columba 2 ).

89.- 2 (CCh SL II p. 1120, 17-19).

90.- Observatorum in Scriptoribus Ecclesiasticis quibus tamen passim et vetustiores utriusque linguae auctores interpositi illustrantur et emendantur Monobiblos. Daventriae, 1651 pp. 193s. Sobre J.F. Gronov, véase: STEF Bugter, J. F. Gronovius en de Annales van Tacitus, Rijksuniversiteit te Leiden. Leiden 1980, 244 págs. 
literarum agnoscere et pronuntiare discant. Quis autem potest dubitare, Germanorum fibel esse corruptum, non ex Latino fibula, sed ex Graecorum $\beta i ́ \beta \lambda_{o} \varsigma \eta \eta \beta \iota \lambda$ íov ut et bibel pro scriptura sacra? In Paciano legimus: cum in hanc quasi fibulam totius Ecclesiae disciplina nodetur. Vel, in hac fibula. Ipsam poenitentiam sic vocat, quod omnem contineat Ecclesiae disciplinam; cuius expedit et catechuminis et fidelibus et poenitentibus recordatione comprimi, retineri et morderi; perinde ut fibula nodat et mordet et continet vestem. Nodare verbum proprium de fibula. Sic Claudiano, tereti nodantur jaspide vestes ${ }^{(91)}$. Idem verbum restituendum Adhelmo cap. IX: Iugalitas, quae ad procreandam posteritatis subolem et liberorum procreandorum gratia licitis connubij nexibus credatur. Legendum, nodatur. Sic enim infra de Chrysanto: hortantur patrem, ut filius blandis connubij nexibus nodaretur. De Davide: antequam copula matrimonij nexu innodaretur. De Samsone: deceptus illecebrosis lenocinij nexibus nodaretur.

En latín tardío fibula no tiene solamente el sentido de "hebilla" para abrochar y sujetar el vestido: Es también un tecnicismo de la retórica y del lenguaje de los astrónomos.

En una carta dirigida al emperador Frontón ${ }^{(92)}$ canta las glorias del humo, del polvo y del descuido, y en los prolegómenos sobre la manera de escribir usa la palabra fibula en un sentido técnico retórico de conclusión añadida elegantemente a un texto breve: ut nouissimos in epigrammatis uersus habere oprtet aliquid luminis, sententia claui uel fibula terminanda est.

En el Computus Paschalis de Cartago la palabra fibula hace, por medio del relativo quibus, de complemento de adnotata: His quoque supradictis columnis aliae septem iunguntur, in quibus kalendarum ianuariarum luna et paschae dominicorum dies adnotantur. Tricesimarius etenim lunae numerus per septenarium numerum ebdomadis diuisus, spatias numero ducenta decem disterminat. Ut autem uniuscuiusque paschae diem inuenias, lunam et feriam, quae fuerit kalendis ianuariis obseruabis, ut lunae cursum tenens, in eadem columna diem inuenies paschae, quod adferiam suprascriptam pertinere uidetur. Hoc idem et in fibulis triginta sequentibus adprobatur, in quibus kalendarum martiarum lunam et feriam per septenarium numerum utrarumque in lunae dierum triginta, ducenta decem spatia inuenies adnotata, nuntiantes certissime fixum uniuscuiusque anni dominicum pasche. Nam et harum fibularum numerum tres aliae ut pediseque columnae secuntur, quae in se embolismorum

91.- El verso entero reza: collectae tereti nodantur iaspide uestes. Cf. Rapt. Proserp. lib. II 40: J. B. HaLL, Claudii Claudiani Carmina, Leipzig 1985 p. 306. Para poner más de manifiesto la falta de paralelismo con Paciano se citan a continuación los pasajes con una cierta amplitud: De Chrysantho: Deinde quidam de contribulibus hortantur patrem, ut filius blandis connubii nexibus nodaretur et illecebroso matrimonii lenocinio vinceretur, quatenus Daria, virgo vestalis satis pulchra et eleganti forma, gemmis auroque radians ad Chrisantum procaciter ingrederetur. Aldhelmi, De virginitate xxxv ed. R. EHwaLd, MGH XV Berolini 1919 p. 278,11 -14. David quoque opinatissimus regum sub ipso pubertatis tirocinio illibata virginitate praeditus antequam copula matrimonii et connubii nexu nodaretur, nonne argutis fibrarum fidibus limphaticum mitigabat et impensa sospitatis gratia freneticum curavit dira pocul tetrorum explosa spiritum vesania? Ib. liii p. 311,11 - 14. Samson ille Nazarenus ab ipsa gracillima cunabulorum aetatula Domino septenis crinibus sacer, antequam fraudulentis Dalilae complexibus caperetur et perfidi pelicatus stupro enerviter deceptus illecebris lenocinii nexibus nodaretur, nondum ferro dempta cincinnorum caesarie quantis miraculorum signis et virtutum rumoribus omni saeculo usque ad id tempus inexpertis effulsisse divulgatur. Ib. liii p. 312, 2-6.

92.- Laudes fumi et pulueris 2. Cf. M. P. J. VAN den Hout, M. Cornelii Frontonis Epistulae, Leiden 1954 I p. 201. 


\section{A. Anglada}

titulos et lunares annos, lineis tensis ex kalendis ianuaris, quotafuerit, curiosis et bene sullicitis planius monstrare coguntur, ut horum circulorum ueritas in omnibus suis ornata monilibus ostendatur. ${ }^{(93)}$

En este pasaje fibula es el ablativo complemento de adnotata, porque in quibus sustituye in fibulis. En adnotare se incluye el concepto de indicación breve. Estas fibulae son como las columnas que permiten reconocer fácilmente los años del saltus lunae en el cómputo pascual. Hay anotación lo mismo en las columnae que en las fibulae, como se deduce de columnis aliae septem iunguntur in quibus... adnotantur. Que las anotaciones eran breves lo evidencia también la frase quae in se embolismorum titulos lunares annos lineis tensis... monstrare coguntur. De estas observaciones se desprende sin lugar a duda que para el computista cartaginés fibula no es, desde luego, una hebilla que abrocha el vestido, sino un escrito breve a modo de sinopsis y resumen.

El paralelismo de significado de fibula entre el computista cartaginés, de mediados del siglo V, y Paciano resulta más relevante por coincidir incluso los verbos adnotare : notetur.

Los diccionarios etimológicos alemanes ${ }^{(94)}$ derivan la palabra Fibel de Bibel por la razón de que la cartilla escolar en que los niños aprenden a leer contienen muchas historias bíblicas. Así Fibel tomaría su origen de una pronunciación infantil que deformaría la primera $b$ de Bibel en $f$ dando Fibel.

De hecho, la palabra alemana Fibel aparece atestiguada por primera vez a principios del siglo XV y más concretamente en un plan de enseñanza de las religiosas clarisas de Kibnitz en Rostock $^{(95)}$. Un vocabulario de Indersdorf (Munich) del año 1419 traduce "Abecedarium, ein ABC oder ein Fibel". Es particularmente interesante el significado de "sermón de reprimenda" (Strafpredigt) o amonestación basada en un texto bíblico. Es éste un sentido muy afín al de fibula en el De Paenitentibus, en que Paciano amonesta con textos bíblicos a sus fieles que no cumplen debidamente la penitencia.

Barth abunda en esta interpretación cuando estima que el alemán fibel es la misma palabra que el latín fibula. El significado de "cartilla" del latín fibula desvirtúa al menos la etimología tradicional de Fibel y hace pensar en el origen latino, por lo menos como más lógico y seguro.

Conclusión: la interpretación que da K. v. Barth de fibulam de Paciano es la correcta y a él pertenece el mérito de haberlo descubierto. El pasaje de Paciano es el primer texto conocido en que aparece fibula en el sentido de manual o vademecum. Por esta razón conservé en mi edición del De Paenitentibus: cum in hanc quasi fibulam totius ecclesiae disciplina notetur y no la indebida corrección nodetur de Galesinio.

93. BR. KRUSCH, Studien zur christlich-mittelalterlichen Chronologie. Der 84järiger Östercyclus und seine Quellen, Leipzig 1880 pp. $138-150$.

94. Véase, por ejemplo, F. KLUGE, Etymologisches Wörterbuch der deutschen Sprache, Berlin 1967 p. 196; Der grosse Duden 7. Herkunftswörterbuch, Mannheim 1963 p. 166 y sobre todo ALFRED EDBE, Trübners deutsches Wörterbuch. In Auftrag der Arbeitsgemeinschaft für deutsche Wortforschung, Berlin 1940 p. 340 s.

95. MG Paed. 38. 47. 


\section{La edición de Paciano usada por K. v. Barth}

Si los Adversariorum libri LX se editan en 1624 y más tarde en 1648 sin variación, Barth sólo pudo conocer el texto de Paciano por alguna de las siete ediciones publicadas hasta 1624 , como son la editio princeps de 1538 , la de Galesinio de 1564 , las cinco primeras de la Bibliotheca Sanctorum Patrum de Marguerin de la Bigne en los años 1575, 1589, 1609 parisinas, 1618 coloniense y 1624 parisina. Carece de toda probabilidad que el erudito de Küstrin hubiese llegado a tener noticia de la última. Tampoco tuvo ocasión de leer ninguno de los manuscritos, porque el Reginensis Lat 331. pertenecía a la Biblioteca de A. Petau ${ }^{(96)}$ y los otros dos estaban también entonces en Francia. Las lecturas erróneas de los Adversaria nos permitirán determinar con certeza la edición de que dispuso K. v. Barth.

Ep I, II 3, 34 (Adv. lib. xlii cap. xxvii col 1920)

quod per totum orbem nullus inventus sit qui te revinceret.

Observa nuestro docto germano: "Vulgo ineptè intus ex abbreviatione". Esta errata intus en vez de inuentus se halla a partir de la segunda edición de la Bibliotheca de M. de la Bigne.

Ep II, VIII 1 (Adv lib. xliii cap xxiix col.1985)

et desperatis quoque peccatoribus falsa bonae conscientiae imago blanditur.

Sólo se puede explicar la corrupción quoque como una enmienda desacertada hecha sobre quique, errata que aparece únicamente en la segunda edición de la Bibliotheca de M. de la Bigne. El texto correcto es quibusque y así fue impreso a partir de la tercera edición de la mencionada Bibliotheca.

Ep I, III 4, 65 (Adv lib. xlii cap. xxvii col. 1920)

Quid? parva nobis de Apostolicis viris, parva primis sacerdotibus, parva de beatissimo Cypriano martyre atque doctore currit auctoritas.

La omisión por errata de la preposición de delante de primis se encuentra únicamente en las dos primeras ediciones de la Bibliotheca de M. de la Bigne. En las ediciones posteriores está ya debidamente restituída.

Así pues, las faltas que se aprecian en el texto de Paciano citado en los Adversaria de Barth comunes con las tres primeras ediciones de las Obras del Obispo de Barcelona lo son también con la cuarta edición, o sea, la segunda de la Bibliotheca de M. de la Bigne; pero las comunes con esta no lo son con las tres primeras.

96.- K. A. De Meyner, Paul en Alexandre Petau en de Geschiedenis van hun handschriften (voornamelijk op grond van de Petau-handschriften in de Universiteitsbibliothek te Leiden), Leiden 1947 pp. 80s. Véase también: Angel Anglad, La 'Editio princeps' de las Obras de Paciano de Barcelona en Miscel.lània Sanchis Guarner II. Quaderns de Filologia. Universitat de València 1984 pp. 17 -22. 
A. Anglada

Conclusión: K. v. Barth en sus Adversaria citó el texto de Paciano por la segunda edición de la Bibliotheca de M. de la Bigne, publicada en el año 1589.

Angel ANGLADA

Universidad de Valencia 